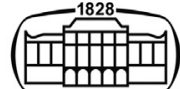

AKADÉMIAI KIADÓ

Journal of Behavioral Addictions

9 (2020) 4, 1093-1097

DOI:

$10.1556 / 2006.2020 .00082$

(c) 2020 The Author(s)

\section{BRIEF REPORT}

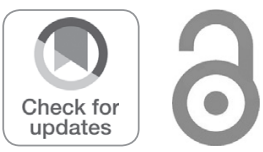

\title{
The prevalence of loyalty program use and its association with higher risk gambling in Australia
}

\author{
PAUL DELFABBRO $^{1 *}$ (๑) and DANIEL L. KING ${ }^{2}$ \\ ${ }^{1}$ University of Adelaide, School of Biological Sciences, Adelaide, Australia \\ ${ }^{2}$ College of Education, Psychology, \& Social Work, Flinders University, Australia
}

Received: May 28, 2020 • Revised manuscript received: August 9, 2020; August 29, 2020 - Accepted: October 12, 2020

Published online: November 4, 2020

\begin{abstract}
Background and aims: Loyalty programs are implemented widely by gambling operators to provide customers with additional prizes and benefits for consistent patronage. The aim of this paper was to examine whether loyalty programs were more commonly reported by higher risk gamblers in large population studies conducted in Australia. Method: This paper examines the prevalence of loyalty program use and the association with problem gambling in Australia using data from seven out of 13 public gambling prevalence surveys conducted over the last decade. Results: Evidence drawn from six of these seven studies showed consistent positive association between loyalty card use and higher risk gambling in venue-based gamblers. At least $40 \%$ of problem gamblers reported loyalty card use compared with only around $10 \%$ of gamblers in general. Discussion: These observations suggest that there is a need to conduct more focused investigations on the utilisation of loyalty programs by higher risk gamblers. Conclusions: It will be important to examine whether loyalty programs encourage or extend gambling sessions, but also how they can be used to facilitate responsible gambling initiatives and inform further behavioural research.
\end{abstract}

\section{INTRODUCTION}

Loyalty programs are a common feature of gambling operations around the world (Wohl, 2018). Often accompanied by a membership card and number, these programs enable gamblers to obtain additional rewards or credits for gambling at a particular venue or on particular products (Prentice \& Wong, 2015; Responsible Gambling Council, 2013). Many of these programs operate on a tiered system whereby the level of membership is determined by the level of play. Such systems operate commonly in casinos and offer: higher tier patrons additional benefits not available to other patrons; access to more exclusive offers; better quality amenities; greater staff attention; and, superior food and beverage services (Min, Raab, \& Tanford, 2016; Shi, \& Prentice, \& He, 2014; Sui \& Baloglu, 2003). The principal aim of these programs is to attract and maintain high value customers and establish trust and loyalty so that these people return to the same venue (Baloglu, Zhong, \& Tanford, 2017; Lucas \& Bowen, 2002; Lucas, Dunn, \& Singh, 2005; Palmer \& Mahoney, 2005).

Loyalty programs commonly operate on a points-for-play system whereby gamblers obtain access to higher tiers and prizes by spending more time and money. Within such systems, the dollar for value assignment is often referred to as the 'step size' (e.g. \$10 for 1 point) and the time to reward as the reward distance (Min et al., 2016; Van Dyke, Jenner \& Maddern, 2016) although different point values may apply to different games and varying methods of benefit

*Corresponding author. E-mail: paul.delfabbro@adelaide.edu. au accrual can be used in these programs. Players learn about their progress from kiosks, customer service desks, or in venue communications. Such systems provide players with an incentive to spend more to get more points (which may provide access to in-venue prizes or greater privileges), but also to continue if they are close to the next tier level. However, not all prizes have to be based on increments. Venues may also award prizes for patrons who are gambling at particular times (e.g. on a particular machine machine), who obtain a particular outcome (e.g. in 
a 'poker machine tournament') or earn more points, or who have a birthday. The capacity to administer such programs arises from players inserting their cards into gaming machines which allows venues to identify and even track the expenditure of individual patrons (Van Dyke et al., 2016).

The fact that loyalty programs potentially encourage higher spending and longer and more frequent visits to venues has raised the question as to whether they: (a) contribute to greater gambling intensity; (b) are more appealing to higher risk gamblers; (c) contribute to gambling harm. As both Wohl (2018) and The Responsible Gambling Council (RGC) (2013) point out, the evidence in support of these questions is remarkably sparse. Prentice and Wong (2015) examined the predictors of problem gambling in 312 people surveyed in Macau and found that problem gamblers were more likely to report being loyal to a casino, based on a series of self-report questions, but found that this relationship did not hold once gambling frequency had been controlled for in a regression model. Wardle (2016) in the UK as well as Min et al. (2016) in the US found evidence for increased expenditure amongst loyalty card members. This was also observed in a study involving a convenience sample of 1,463 Electronic Gaming Machine (EGM) gamblers in Australia tracked over 18 months (Van Dyke et al., 2016). This study showed that loyalty card use was associated with gambling 1.37 times more frequently and 1.23 times longer. Loyalty card users were 2.28 times more likely to be moderate risk or problem gamblers on the PGSI and 1.33 times more likely to report incidents of binge gambling.

\section{THE PRESENT ANALYSIS}

There are currently very little data available to researchers and policy-makers on the general prevalence of loyalty program use and its potential link with higher risk gambling in the general population. This topic is important for two principal reasons. The first is because there are regulatory concerns about whether loyalty program incentives might encourage greater gambling expenditure. The second is that loyalty programs can potentially be used as a vehicle for implementing responsible gambling features (e.g. messaging or limit setting). A third area of interest arises from the fact that loyalty programs could be used as a source of research data relating to individual gamblers that can provide insights into important aspects of gambling behaviour to help inform harm minimisation strategies (e.g. Wardle, 2016). In this paper, we provide a summary of the evidence base drawn from major prevalence studies in Australia relating to the prevalence of loyalty program use in the gambling population and potential associations with higher risk gambling.

\section{DATA SOURCES}

An audit was conducted of all Australian prevalence studies conducted in the last 10 years (2011-2020). Seven of these 13 surveys included questions relating to loyalty card use
Table 1. Summary of major Australian prevalence surveys: 20112020: sample details and participation rates

\begin{tabular}{lcrc}
\hline State & Year & \multicolumn{1}{c}{$N$} & \% Problem gambling \\
\hline NSW & 2019 & 10,012 & 1.0 \\
QLD & 2012 & 15,000 & 0.5 \\
QLD & 2017 & 15,000 & 0.5 \\
SA & 2012 & 9,508 & 0.6 \\
SA & 2018 & 20,017 & 0.7 \\
TAS & 2011 & 4,303 & 0.7 \\
VIC & 2014 & 13,554 & 0.8 \\
\hline
\end{tabular}

Sources: NSW: Browne et al. (2019); SA: Department of Communities and Social Inclusion (2012); SA: Woods, Sproston, Brook, Delfabbro, and O’Neil (2018); TAS: ACIL Allen Consulting (2011); VIC: Schottler Consulting (2015).

(Table 1). Each of the surveys was conducted using a telephone survey methodology, probability-based sampling and utilised a dual-frame methodology (land-lines and mobile/ cell-phone numbers were called). Each survey used the Problem Gambling Severity Index (PGSI) (Ferris \& Wynne, 2001) as the principal problem gambling screening measure. All PGSI comparisons were based on the standard classifications, where scores of $8+$ in the surveys were used to indicate problem gamblers; scores of 3-7, moderate gamblers; 1-2, low risk gamblers; and, scores of 0 , non-problem gamblers. In six of the seven studies, respondents who reported visiting gambling venues were asked whether they were members of a loyalty program or held a loyalty card. In Victoria (2014), the question was only asked of EGM gamblers (binary coding, participated or did not participate) and referred specifically to the Crown Rewards program so that this figure cannot be readily compared with the others. In Tasmania (2011), respondents were asked if they used a loyalty card 'most of the time' or 'always' when they gambled, so that these questions also cannot be so easily compared with the others. Full data for the South Australian (2018) survey was available to the researchers to allow additional analyses. Australian studies were chosen as the focus of the paper because this made it possible to consolidate results from a concentrated period of studies that used similar methodologies in jurisdictions with similar regulatory regimes and gambling markets.

\section{RESULTS}

A summary of the four surveys that with similar and comparable data is displayed in Table 2. The results indicate some variability, but it appears that approximately $10 \%$ of non-problem gamblers; around 20\% low risk gamblers, $33 \%$ of moderate risk gamblers and over $40 \%$ of problem gamblers, report belonging to a loyalty card program. Across all surveys there is a clear upward trend, with higher risk gamblers more likely to report having a loyalty card. A series of pairwise comparisons conducted using proportion difference tests showed (using the weighted averages) that the percentage of gamblers reporting loyalty card use was 
Table 2. Prevalence of loyalty card use by PGSI status

\begin{tabular}{lccccc}
\hline & $N$ & Non-problem $\%$ & Low risk $\%$ & Moderate risk \% & Problem \% \\
\hline SA (2011) & 5,189 & 9 & 17 & 25 & 41 \\
NSW (2019) & 1,074 & 7 & 16 & 22 & 30 \\
QLD (2012) & 11,100 & 10 & 24 & 42 & 39 \\
QLD (2017) & 10,620 & 12 & 26 & 33.3 & 59 \\
$M_{w}$ & & 10.5 & 23.2 & 46.5 \\
\hline
\end{tabular}

Note: SA (2011) asked venue gamblers; NSW asked EGM gamblers; QLD asked all gamblers.

Table 3. Logistic regression: loyalty card use as a predictor of problem gambling

\begin{tabular}{lcrcc}
\hline & \multicolumn{3}{c}{ Odds- } \\
& \multicolumn{1}{c}{ Ward } & ratio & $95 \%$ conf Int \\
\hline Monthly EGMs & 2.32 & $116.51^{* *}$ & 10.18 & $6.68-15.51$ \\
Gender & -0.541 & $7.61^{* *}$ & 0.582 & $0.40-0.86$ \\
Loyalty card use & -1.023 & $27.52^{* *}$ & 0.359 & $0.25-0.53$ \\
Constant & -2.315 & & & \\
\hline
\end{tabular}

$* * P<0.01$

highest for problem gamblers with different differences observed between all other groups: Problem gamblers > Moderate risk $>$ Low risk $>$ Non-problem gamblers.

In Victoria in 2014, it was found that $45 \%$ of EGM gamblers reported having a Crown Casino Loyalty Rewards card: $40 \%$ of non-problem gamblers; $53 \%$ of low risk gamblers; $46 \%$ of moderate-risk gamblers; and, $61 \%$ of problem gamblers. In South Australia in 2012, it was found that $11 \%$ of all gamblers reported using a loyalty card, but that $28.1 \%$ of moderate risk and problem gamblers used one (once again a significantly higher level of usage than for other gamblers) as based on a proportion difference test $(P<$ $0.001)$. Finally, in Tasmania in 2011, there was no difference between the PGSI risk groups in the percentage reporting using a loyalty card 'most of the time' or 'always' when they played (11\%). This figure is, of course, not the same as the other figures which principally related to the general use of programs rather than how often they used them.

\section{LOYALTY CARD MEMBERSHIP AS A PREDICTOR OF PGSI AFTER CONTROLLING FOR OTHER VARIABLES}

Given the availability of data in South Australia in 2011, it was possible to examine whether engagement in loyalty programs ( $1=$ Yes, $2=$ No) was associated with problem gambling after controlling for potential confounding factors; namely, gender ( $1=$ Male, $2=$ Female $)$ and the frequency of EGM gambling $(0=$ No, $1=$ Yes $)$. Gender was included because males tend to report greater gambling involvement in almost all Australian studies (see Hing, Russell, Tolchard, \& Nower, 2016). Problem gambling was set as the dependent measure $(0=$ Not problem, $1=$ Problem $)$. The model correctly classified $97 \%$ of cases. Table 3 summarises the results. It was found that loyalty card users were $(1 / 0.359=$ 2.79 times) more likely to be problem gamblers even after controlling for gambling frequency and gender.

\section{DISCUSSION}

Overall, the results suggest that loyalty card or program use increases with the level of gambling risk. Around 15\% of all gamblers in the general population report using loyalty programs, but this figure is much higher when the denominator is restricted to just venue-based or EGM gamblers. Our estimates suggest that over $40 \%$ of problem gamblers in Australia are loyalty card users and this percentage gradually decreases as one progresses down the PGSI classifications. These findings are generally convergent with the findings for Van Dyke et al. (2016) in Australia as well as Wardle (2016) in the UK who found associations between loyalty card use and more frequent gambling, longer sessions and higher expenditure. However, as Prentice and Wong (2015) and Van Dyke et al. (2016) point out, it is not clear whether loyalty program membership is necessarily causally related to problem gambling. Regular gamblers may sign up to loyalty programs just because they are available ('nothing to lose') and because these may yield occasional benefits. In support of this view, the studies show that people who own loyalty cards rarely use them at all, or very infrequently (only $11 \%$ in Tasmania reported frequent use). Those who score higher on the PGSI are also usually frequent or regular gamblers so that, as Prentice and Wong (2015) showed, it may be that the association between loyalty program and problem gambling is confounded with gambling frequency in some surveys. Nevertheless, using data from one State, we were able to show that the relationship still holds even after controlling for gambling frequency.

Confirmation of an association between problem gambling and loyalty card use is important for several reasons. First, as Van Dyke et al. (2016) and Wohl (2018) have pointed out, it may be important to consider the possibility that loyalty programs could contribute to gambling harm. Although qualitative evidence from Van Dyke et al.'s (2016) study suggested that problem gamblers did not raise concerns (perhaps due to socially desirable responding), the data still suggested that loyalty cards encourage people to gamble more frequently and intensively. It may also be that loyalty programs are an exacerbating factor, not necessarily when some people are actively gambling anyway, but when 
they make the decision to stop gambling. That is, when considering abstinence or controlled gambling, many problem gamblers may continue to receive marketing; will be confronted with the sunk-cost of ceasing to gamble after having achieved a higher membership tier (or be close to the next one); and, may miss out on the benefits that the loyalty program provides (e.g. extra prizes or feeling important in the venue).

The knowledge that problem gamblers are more likely to be engaged in loyalty programs may also be useful from a responsible gambling or harm minimisation perspective. As Wohl (2018) points out, loyalty programs can provide a vehicle for targeted messaging, reminders, pre-commitment or budget setting systems (e.g. Auer, Hopfgartner, \& Griffiths, 2018, 2019; Schottler Consulting, 2010; Thomas et al., 2016). They also provide a potential vehicle through which to capture important data about the nature of gambling (e.g. Gainsbury, 2011; Livingstone, Woolley, Zazryn, Bakacs, \& Shami, 2008; Wardle, 2016), including gambling patterns (e.g. predictive algorithms). Loyalty program data may also capture the relative popularity of certain machines and how people respond to responsible gambling features (Livingstone et al., 2008; Parke, Parke, \& Blaszczynski, 2016). In Australia, the data would appear to indicate some capacity for at least $40 \%$ of problem gamblers to be engaged with features of this nature, but it is acknowledged that this engagement would principally be confined to EGM gamblers who choose to use their loyalty cards (what casinos often refer to as carded-play). Insights into the potential ways in which loyalty programs might be applied in harm minimisation contexts are evident in a small, but growing, literature (see Gainsbury, 2011; Philander, 2013; Wohl, 2018 for useful reviews). For example, Wohl, Davis and Hollingshead (2017) showed how providing personalised feedback to loyalty program holders appeared to reduce subsequent expenditure. Similarly, Wood and Wohl (2015), in an evaluation of the Svenska Spel's responsible gambling tool Playscan, showed that higher risk gamblers reduced expenditure and deposit amounts if they used the tool.

\section{METHODOLOGICAL CONSIDERATIONS AND CONCLUSIONS}

It is important to acknowledge the limitations of this paper. The paper focused on only a single jurisdiction (Australia) and is based on self-report data so that there may be recall biases. There were also data limitations: in that most studies did not capture the nature and type of loyalty program used (e.g. casino vs. other venue) and how often these were used. Nevertheless, the studies examined appear to provide consistent evidence that loyalty programs are significantly associated with problem gambling and are associated with increased gambling involvement. The results indicate that there is considerable scope for more detailed analysis of the potential risks and benefits of loyalty programs. On one hand, there should be a particular focus on the ways in which loyalty programs are used by higher risk gamblers, their responses to incentives, and whether exposure to special offers trigger new gambling sessions or extends existing ones. On the other, further exploration of the potential role of loyalty programs and the associated data should be pursued as part of responsible gambling initiatives and in collaborative work involving researchers, regulators and industry groups (Gainsbury, 2011; Wohl, 2018).

Funding sources: This paper was funded independently with no support from government, industry or party external to the University.

Authors' contribution: First draft of paper (PD); Revisions (DK).

Conflict of interest: None to declare.

\section{REFERENCES}

ACIL Allen Consulting (2011). Second social and economic impact study of gambling in Tasmania. Hobart: Tasmanian Government Department of Treasury and Finance.

Auer, M., Hopfgartner, N., \& Griffiths, M.D. (2018). The effect of loss-limit reminders on gambling behaviour: A real-world study of Norwegian gamblers. Journal of Behavioral Addictions, 7(4), 1056-1067.

Auer, M., Hopfgartner, N., \& Griffiths, M. D. (2019). An empirical study of the effect of voluntary limit-setting on gamblers' loyalty using behavioural tracking data. International Journal of Mental Health and Addiction, 17, 1-12.

Baloglu, S., Zhong, Y.Y., \& Tanford, S. (2017). Casino loyalty: The influence of loyalty program switching costs and trust. Journal of Hospitality \& Tourism Research, 41, 846-868.

Browne, M., Rockloff, M., Hing, N., Russell, A., Murray-Boyle, C., \& Rawat, V. (2019). NSW gambling survey, 2019. Sydney: NSW Responsible Gambling Fund.

Department of Communities and Social Inclusion (2012). Gambling prevalence in South Australia. Adelaide: DCSI.

Ferris, J., \& Wynne, H. (2001). The Canadian problem gambling Index final report. Phase II final report to the Canadian Interprovincial Task Force on Problem Gambling. Canadian Centre for Substance Abuse.

Gainsbury, S. (2011). Player account-based gambling: Potentials for behaviour-based research methodologies. International Gambling Studies, 11, 153-171.

Hing, N., Russell, A., Tolchard, B., \& Nower, L. (2016). Risk factors for problem gambling: An analysis by gender. Journal of Gambling Studies, 32, 511-534.

Livingstone, C., Woolley, R., Zazryn, T., Bakacs, L., \& Shami, R. (2008). The relevance and role of gaming machine games and game features on the play of problem gamblers. Adelaide: Independent Gambling Authority. 
Lucas, A.F., \& Bowen, J.T. (2002). Measuring the effectiveness of casino promotions. International Journal of Hospitality Management, 21, 189-202.

Lucas, A., Dunn, W., \& Singh, A. (2005). Estimating the short term effect of free-play offers in Las Vegas hotel casino. Journal of Travel \& Tourism Marketing, 18, 53-68.

Min, J.H., Raab, C., \& Tanford, S. (2016). Improving casino performance through enhanced loyalty programs. Journal of Hospitality Marketing \& Management, 25, 61-88.

Palmer, R., \& Mahoney, E. (2005). Winners and losers: Segmenting a casino loyalty programme. International Gambling Studies, 5, 271-287.

Parke, J., Parke, A., \& Blaszczynski, A. (2016). Key issues in produced-based harm minimisation. London: The Responsible Gambling Trust.

Philander, K. (2013). Identifying high-risk online gamblers: A comparison of data mining procedures. International Gambling Studies, 14, 53-63.

Prentice, C., \& Wong, I. A. (2015). Casino marketing, problem gamblers or loyal customers?. Journal of Business Research, 68, 2084-2092.

Responsible Gambling Council (2013). Insight: Responsible gambling best practices for player incentives: Land-based venues. Toronto: RGC.

Schottler Consulting (2010). Major findings and implications: Player tracking and precommitment trial. Adelaide: S.A. Treasury.

Schottler Consulting (2015). Study of gambling and health in Victoria. Findings from the Victorian prevalence study 2014. Melbourne: VRGF.

Shi, Y., \& Prentice, C., \& He, W. (2014). Linking service quality, customer satisfaction and loyalty in casinos: Does membership matter?. International Journal of Hospitality Management, 40, $81-91$.
Sui, J., \& Baloglu, S. (2003). The role of emotional commitment in relationship marketing: An empirical investigation of a loyalty model for casinos. Journal of Hospitality \& Tourism Research, $27,470-489$.

Thomas, A., Christensen, D., Deblaquiere, J., Armstrong, A., Moore, S., Carson, R., et al. (2016). Review of electronic gaming machine pre-commitment features: Limit setting. Melbourne: Australian Institute of Family Studies.

Van Dyke, N., Jenner, D., \& Maddern, C. (2016). The role of loyalty programs in gambling: Final report of findings from audit of electronic gaming machine venues, literature review, online discussion boards and longitudinal telephone survey. Melbourne, Gambling Research Australia.

Wardle, H. (2016). People who play machines in bookmakers: Secondary analysis of loyalty card survey data. London: Responsible Gambling Trust.

Wohl, M. J. A. (2018). Loyalty programmes in the gambling industry: Potentials for harm and possibilities for harmminimization. International Gambling Studies, 18, 495511.

Wohl, M. J. A., Davis, C. G., \& Hollingshead, S. J. (2017). How much have you won or lost? Personalized behavioural feedback about gambling expenditures regulates play. Computers in Human Behavior, 70, 437-445.

Woods, K., Sproston, K., Brook, K., Delfabbro, P., \& O’Neil, M. (2018). Gambling prevalence in South Australia. Adelaide: Department of Human Services.

Wood, R. T. A., \& Wohl, M. J. A. (2015). Evaluating the effectiveness of a responsible gambling behavioral feedback tool for reducing the expenditure of at-risk players. International Gambling Studies, 15, 324-339. 